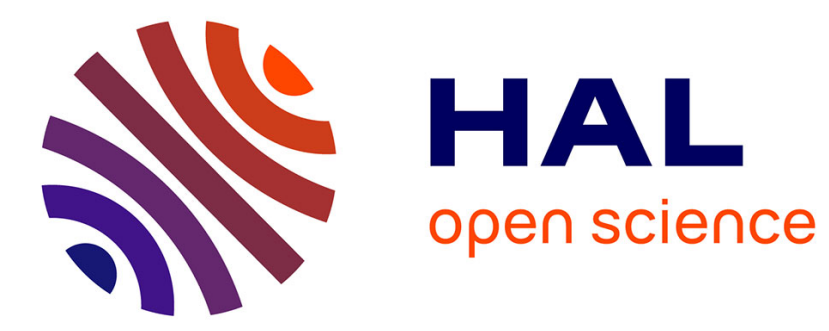

\title{
Discussions on an Interval Arithmetic Standard at Dagstuhl Seminar 08021
}

\author{
R. Baker Kearfott, John D. Pryce, Nathalie Revol
}

\section{To cite this version:}

R. Baker Kearfott, John D. Pryce, Nathalie Revol. Discussions on an Interval Arithmetic Standard at Dagstuhl Seminar 08021. Dagstuhl Seminar 08021: Numerical Validation in Current Hardware Architectures, Cuyt, Annie and Krämer, Walter and Luther, Wolfram and Markstein, Peter, Jan 2008, Dagstuhl, Germany. pp.1-6, 10.1007/978-3-642-01591-5_1 . inria-00545059

\section{HAL Id: inria-00545059 \\ https://hal.inria.fr/inria-00545059}

Submitted on 15 Dec 2010

HAL is a multi-disciplinary open access archive for the deposit and dissemination of scientific research documents, whether they are published or not. The documents may come from teaching and research institutions in France or abroad, or from public or private research centers.
L'archive ouverte pluridisciplinaire HAL, est destinée au dépôt et à la diffusion de documents scientifiques de niveau recherche, publiés ou non, émanant des établissements d'enseignement et de recherche français ou étrangers, des laboratoires publics ou privés. 


\title{
DISCUSSIONS ON AN INTERVAL ARITHMETIC STANDARD AT DAGSTUHL SEMINAR 08021
}

\author{
R. BAKER KEARFOTT, JOHN PRYCE, AND NATHALIE REVOL
}

\section{BACKGROUND}

Efforts have been made to standardise interval arithmetic for over a decade. The reasons have been to enable more widespread use of the technology, to enable more widespread sharing and collaboration among researchers and developers of the technology, and to enable easier checking that computer codes have been correctly programmed. During the late 1990's, the first author of this report led such a project to introduce an interval data type into the Fortran language. One reason for failure of that effort was the Fortran language standardization committee's lack of familiarity with interval technology and consequent caution. Another was misunderstanding between the Fortran standardization committee's basic tenets on standardizing interline optimization and some views expressed by members of the interval analysis community. A third was confusion over how extended interval arithmetic (arithmetic dealing with division by intervals that contain zero) should be handled. This was coupled with a heavy committee load associated with other projects, such as standardizing an interface for interoperability with "C" language programs.

Since then, the interval analysis community has studied and gained additional understanding of extended interval arithmetic. One such study is [3], a systematization of the options. Another, with a particular point of view, is Prof. Kulisch's contribution to this volume. Extended arithmetic remains a controversial part of efforts to standardise the arithmetic, particularly whether the underlying model should consider $-\infty$ and $\infty$ to be numbers in their own right or if $-\infty$ and $\infty$ should just be considered placeholders to describe unbounded sets of finite real numbers. A practical consequence is a difference in how $0 \cdot \infty$ is defined. Nonetheless, our understanding and thinking about this issue is clearer than a decade ago. This, coupled with the desire to have a standard, should lead to progress.

A standard is concurrently being developed for interval arithmetic in $\mathrm{C}++$. This work is presently slated to become a technical report (something that is generally implemented by compiler developers and is expected to become an integral part of a future standard).

In the mean time, perhaps the most widely used interval arithmetic system is that underlying INTLAB [4], although various other systems, such as PROFIL / BIAS [1, 2], also are in wide use.

This note is current as of mid-July, 2008.

\section{Proceedings at the Seminar}

The context of this meeting was that

- The IFIP Working Group 2.5 on Numerical Software had written in September 2007 to the IEEE 754 Revision committee (IEEE754R) strongly supporting the inclusion of interval arithmetic (IA) in the forthcoming standard (P754).

- IEEE754R had asked Prof Kulisch, in collaboration with others, to produce a proposal for inclusion in the standard, which he had submitted in October 2007. It is called the KK proposal here because its detail is based on the 2006 paper "Hardware support for interval arithmetic" by Kirchner and Kulisch.

- From then up to and including at the Dagstuhl meeting, several leading workers in intervals, as well as members of IEEE754R, expressed broad support for the proposal but felt it lacked some crucial detail and could not be included in the standard without further work.

A first discussion on the topic was held at Dagstuhl on Thurs 10 Jan. The following aims to summarise this discussion. Speakers recorded are:

Date: July 2, 2008. 


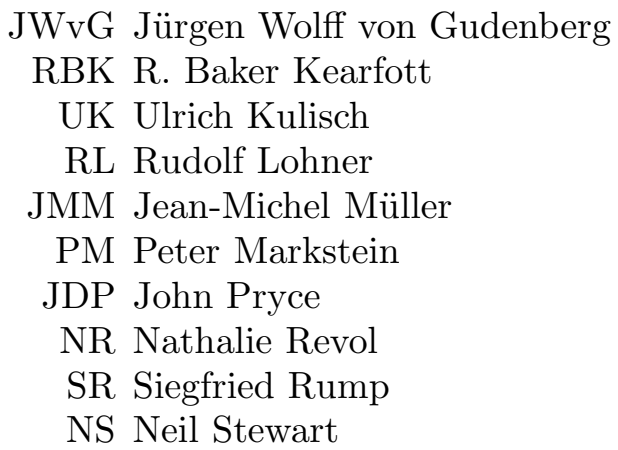

RBK, leading the discussion, began by saying he believed the lack of consensus, and time constraints, made it impossible to include the Kulisch proposal in the current P754R revision. Instead, we should ask IEEE's authority for starting a new committee with wide participation from the interval community, to produce an IA standard in a longer timescale.

PM said that IA had been in the draft standard but too little of the detail was agreed by everyone so it was dropped. If we could agree on the Kulisch proposal or something close, we were in good shape to have it included in IEEE754 in a short time - provided we could muster enough people willing to work on the detail.

JMM said it was important to include people from IEEE754R, to ensure compatibility with that standard.

RBK proposed the motion:

"That the KK proposal be supplied to IEEE754R as the basis for an initial draft of a free-standing IA standard, initially independent of P754R, to be worked on by a new committee set up for the purpose."

If this were carried, we should write a suitable letter to IEEE with a preliminary list of people who had expressed interest in participating.

UK: He had already essentially done this when submitting his proposal on 10th October.

JDP: Then the purpose of this meeting was to obtain wider consensus.

NS: The new committee needed members with a wide range of expertise - hardware, software engineering, people from industry, numerical analysts, members of research teams, ...

Possible members were suggested, including people from

- Intel, say Herbert Cornelius, since the MK library includes IA.

- Current IEEE754R committee, say Van Snyder.

- ISL (Interval Subroutine Library), say Baker Kearfott and John Pryce.

- INRIA, say Nathalie Revol and Guillaume Melquiond.

RL and JWvG were willing to serve on the committee. UK might do so.

SR raised a more general question about the work. There are several underlying mathematical models on which IA can be based. The Kulisch proposal only supported one of these. There were several that he regarded as an acceptable basis for practical interval computation. Should the committee study several models with the aim of (a) choosing the one it thought best and/or (b) creating a standard that supports more than one model? These were not mutually exclusive options.

RBK proposed wording:

"There are several well developed IA philosophies. The committee will study and integrate these, so that the resulting standard does not make it too difficult to implement any of them."

JMM: Probably

"the best IA philosophy to choose is the one that is easiest to build other models on top of".

It was agreed that this should be put in the proposed letter.

NR mentioned the Hickey, Ju and van Emden interval model. The authors should be invited.

SR would consider who from the Hamburg group might take part. 
RBK mentioned that members of the $\mathrm{C}++$ interval standard group (Brönnimann, Melquiond, Pion) should all be invited.

The motion, as such, was dropped and it was agreed that a letter should be written proposing the new working group, with a remit based on $(1$ and (2, and with a preliminary list of participants.

It was also agreed to start a discussion forum on the Reliable Computing mailing list, to find more participants, gather opinions, and clarify the points of consensus and most crucially the main points of disagreement.

The meeting closed. A letter was drafted by RBK, JDP and NR [Is that right Baker?]. Further discussions took place the following day and the letter was revised as a result. It was sent, dated 11th Jan 2008, to Dr Dan Zuras, Chair IEEE 754 Revision Committee (IEEE754R), with a copy to Dr. R. F. Boisvert, Chair, IFIP Working Group 2.5. Signatories supporting the letter (listed in order of signing) were:

R. Baker Kearfott, W. Luther, J.D. Pryce, Nathalie Revol, S.M. Rump, Guillaume Melquiond, Michel Kieffer, Vincent Lefèvre, C. Keil, Andreas Rauh, Jean-Michel Müller, Nicolas Louvet, Jean-Luc Lamotte, Markus Neher, Rudolf Lohner, Peter Markstein.

\section{Subsequent Developments}

Subsequently, the first and third authors of this note collected a list of electronic mail and postal addresses for interested persons. Fortunately, these interested persons included those who were unable to attend the meeting (during the last hours of the seminar) as well as those against formation of the new committee, in favor of trying to get IEEE to adopt the results of IFIP Working Group 2.5. The three authors of this note also worked with Bob Davis, chair of the IEEE Microprocessor Standards Committee, to get approval of a Project Authorization Request through the New Standards Committee, for work on a stand-alone standard (separate from the IEEE standard for floating point arithmetic) for interval arithmetic. Authorization for the project passed unanimously on June 11, 2008. The next step will be an organizational meeting, scheduled to be held in conjunction with SCAN-2008 in El Paso, Texas, USA, September 29 to October 3, 2008. The agenda for this organizational meeting, being discussed by the three authors of this note, will include election of officers ${ }^{1}$ and agreement on procedures for decision-making. Such procedures need to include all interested parties ${ }^{2}$, and should be such that all will respect the decisions made according to the procedures. Through these procedures, we strive to gain wider and unambiguous acceptance, at all levels, than the document produced by IFIP Working Group 2.5.

Although the project is for a stand-alone document, a goal is to make it consistent with the IEEE standard for floating point arithmetic, for possible eventual incorporation into that standard. Some (but not all) issues related to this are

- the underlying mathematical model for the real numbers,

- requirements that features be implemented in hardware (or not),

- the set of features that are implemented.

The normal time frame for such a project is five years, although there is hope to complete the process sooner.

\section{REFERENCES}

[1] Olaf Knüppel. PROFIL/BIAS - A fast interval library. Computing, 53(3-4):277-287, September 1994.

[2] Olaf Knüppel. PROFIL/BIAS v 2.0. Bericht 99.1, Technische Universität Hamburg-Harburg, Harburg, Germany, Februar 1999.

[3] John Derwent Pryce and George F. Corliss. Interval arithmetic with containment sets. Computing, 78(3):251-276, 2006.

[4] Siegfried M. Rump. INTLAB-INTerval LABoratory. In Tibor Csendes, editor, Developments in Reliable Computing: Papers presented at the International Symposium on Scientific Computing, Computer Arithmetic, and Validated Numerics, SCAN-98, in Szeged, Hungary, volume 5(3) of Reliable Computing, pages 77-104, Dordrecht, Netherlands, 1999. Kluwer Academic Publishers.

\footnotetext{
${ }^{1}$ Presently, Nathalie Revol is serving as interim chair, and R. Baker Kearfott is serving as interim Vice Chair.

${ }^{2}$ And thus should allow for email votes and conference call discussions.
} 